\title{
Truth Telling to Life-Threatened and Dying Patients in Israel: Can Legislation improve it?
}

\author{
Riad Abu Rakia ${ }^{1}$, Khaled Awawdi ${ }^{2}$ and Mahdi Tarabeih*3 \\ ${ }^{1}$ Department of palliative care, School of nursing sciences, Israel \\ ${ }^{2}$ Lecturer in Nursing Sciences, Israel Academic College, Israel \\ ${ }^{3}$ Faculty of Nursing Sciences, Tel Aviv-Jaffa Academic College, Israel
}

Received: February 20, 2018; Published: February 27, 2018

*Corresponding author: Mahdi Tarabeih, Senior lecturer, Faculty of Nursing Sciences, Tel Aviv-Jaffa Academic College, Jaffa, Israel, Sakhnin, post office: 6044, postal code: 3081000, Tel: 972-46745785; Email: tarabeih1969@gmail.com

\section{Abstract}

Background: Truth-telling by doctors to patients is a basic moral rule in developed healthcare systems. Not to tell the truth jeopardizes staff-patient trust, undermines the patient's capacity for autonomy, and deprives the terminally-ill of a 'good death'. Yet non-truth-telling is still common. This study explores and measures the extent of non-truth-telling to cancer patients in Israel's modern health care system, why it happens and what consequences it leads to.

Research Design and Methods: This Mixed Methods study of doctors working regularly in the field of palliative care, in both hospital, community and home care settings centred on two main tools, the first a qualitative structured in-depth interview of 15 doctors (from oncology, hospice home care and family medicine); the second a much longer quantitative self-administered questionnaire for 90 practitioners (30 hospital oncologists, 30 home care specialists, and 30 family medicine specialists). The sample was made fully representative of the research population. The sampling method combined cluster, directed and convenience sampling. Data were analysed by content analysis and descriptive statistics (chiefly means and correlations).

Findings: Most oncologists had poor knowledge and a negative opinion of the 2005 act of parliament drawn up to regulate the care and treatment of terminally-ill patients. They knew and thought equally little of the palliative care approach which the Act mandated. Most doctors did not tell patients the full truth about their medical condition and avoided holding an end-of-life conversation with them or discussing Advance Medical Directives, largely out of fear and lack of the emotional resources and communications training required. Most thought truth telling took away hope and that hospice care approximated euthanasia. Many/most were reluctant to face the 'failure' implied in even discussing the transfer of a patient to palliative care. All doctors thought it was another doctor's responsibility to break bad news to patients. There was a huge variance in approach to end-of-life care between hospital oncologists and home care specialists. The consequences of the above were that few patients were given the chance to plan the end-of-life they wanted for themselves and that palliative and hospice care were very much under-used.

Main Conclusion: Israeli oncologists are too fearful of patient-centred end-of-life care to be left in sole charge of it. Shared decisionmaking by all members of a multidisciplinary team would help take the responsibility off oncologists, as well as ensure a higher quality of decision-making. Medical training needs to prepare health care staff for interdisciplinary teamwork. Not sharing data/ decisions with the patient threatens both their autonomy and the quality of the decisions made without their input. The Israel Ministry of Health needs to take initiatives to firmly clarify the provisions of the 2005 Act, to provide and enforce training in its requirements, and to firmly apprise oncologists of their duty to break bad news and conduct the end-of-life conversation most patients need.

Keywords: Advance Medical Directives; Doctor-patient communication; End-of-life care; End-of-life conversation; A good death; Hospice care; Oncologist; Palliative care; Terminally-Ill Patients Act; Truth telling

\section{Background}

Truth-telling, such as doctors telling the truth about a patient's illness, prognosis and treatment plan to the patient and/or their family is a basic moral rule in the western healthcare system. Not to

tell the truth can be viewed as jeopardizing trust in the staff-patient relationship, intruding on the patient's existential integrity and undermining the patient's capacity for autonomy [1]. Non-truth- 
telling can also mean that no Advance Medical Directives (AMDs) and drawn up and no end-of-life (EoL) planning carried out. Yet in this 21st centurynon-truth-telling is still common. This study explores and measures the extent of non-truth-telling to cancer patients in Israel's modern health care system, why it happens and what consequences it leads to. The findings it discusses are drawn from the author's doctoral research carried out between 2012 and 2014.

\section{Research Design and Methods}

There were two main tools. The first was a qualitative structured in-depth interview by the author of 15 doctors, five each from the fields of oncology, hospice home care and family medicine. It asked how they saw the Terminally-Ill Patients Act being implemented, about their approach to the care of terminally-ill patients and palliative and hospice care, about their conduct of EoL and AMD conversations, about coping with the challenge of truth-telling and communications skills, about the barriers to transferring patients to hospice and palliative care. The second tool was a much longer quantitative self-administered questionnaire for 90palliative care practitioners (30 hospital oncologists, 30 home care specialists, and 30 family medicine specialists) covering their knowledge of, and attitudes to, topics such as the implementation and core principles of palliative care and Israel's Terminally-Ill Patients Act, communication issues such as truth telling, drawing up AMDs and EoL planning, the handling of ethical issues in palliative care and the Act's implementation, such as the transition from curative to palliative care.

The research population for the study was all the doctors working regularly in the field of palliative care, in hospital, community and home care settings. The hospital sector was represented by hospital doctors working in a range of departments (family medicine, geriatrics, internal medicine, oncology and others). The community medicine sector was represented by doctors working

A. In community clinics and

B. Home-care units. The sample was made representative of the research population by ensuring that $20 \%$ of the doctors sampled were Arab-Israelis, that it was geographically heterogeneous and that all four major health management organizations participated. The sampling method combined cluster sampling, directed and convenience sampling. Data were analysed by content analysis and descriptive statistics (chiefly means and correlations).

\section{Israeli's Health Care System and its Provision of EoL Care}

Israel's population has for decades been served by an advanced health care system which aims to emulate American and European best practice. Since 2005 the Israeli healthcare system has been making a strong effort to improve its medical training new graduates are very soon involved in clinical care, of which the care of terminally-ill patients will be part and only a small minority of them will have been trained for this element of their daily ward practice. In Israel as elsewhere it is usually regular doctors and nurses who are often 'left' to care for dying patients, and many feel unprepared for this role [2]. It is clear that end-of-life training is more conspicuous by its absence than presence and that what did exist was not powerful enough to give trainees new insights or alter entrenched attitudes. Palliative care was provided in the main in Israeli general hospitals. Hospice care was available for the six months before death but, in practice, its duration varied widely, suggesting different perspectives on the appropriate timing for the transition from curative care to palliative care.

At the time of this research the 76 beds in three hospice units made up a nationwide bed-population ratio of 1.02 per 100,000 , much lower than the ratio of 5 per 100,000 recommended by the Oxford Textbook of Palliative Medicine. The four main health management organizations also operated some eighty Home Care Units which provided medical, nursing and rehabilitation care across the country for bed-ridden persons in their own homes. In 2005 the Terminally-Ill Patients Act was passed. The Act was designed to regulate the care and treatment of incurable, terminally-ill persons, striking a balance between the values of the sanctity of life, recognition of the patient's autonomy of choice, and the importance of the quality of life beyond the importance of life itself. It instituted the instrument of Advance Medical Directives (AMDs) by which an individual states their wishes as to how they should be medically treated should they become terminallyill and lose lucidity of mind. These advance instructions may be designed to rule out life-prolonging treatment or to constrain attending physicians to give such treatment even when they do not consider it medically justified. A patient's right to consent or not to any particular form of treatment had already been set out in the Patients' Rights Act, 1996 [3].

The provisions and non-provisions of the 2005 Act most relevant to truth-telling were the following:

a) It required that the patient be given full information as to his/her treatment and care choices, according to their capacity to take that information in. It lay down that the patient had the right to know, the right to be told the truth and the right to prepare for death.

b) It defined the concepts of a "terminally ill patient" and an "end-stage patient".

c) It introduced the concept of Advance Medical Directives and required doctors to respect them.

d) It lay down that any decision in AMDs shall be made only by the individual them self and of their free choice, not by their family members and not according to any other consideration.

e) It laid down the importance of alleviating pain and suffering even if this involved a reasonable risk of the patient's death,

f) It stressed the importance of the "personal physician" holding an end-of-life conversation with the patient as a key to enabling the patient to realize the above-mentioned rights, but it did not specify who that physician is: 


\section{Findings}

\section{What Truth do Patients not get?}

We can distinguish here between

a) Truth telling about the patient's illness, its prognosis and treatment plan, and

b) Truth telling about EoL planning, AMDs and the resort to palliative care (see Discussion).

i. $\quad$ No less than $78 \%$ of doctor-respondents admitted giving their patients only partial information about their medical condition.

ii. For a variety of reasons the majority of doctors avoided end-of-life conversations, at the best preferring to wait for the patient to broach the issue..

iii. In the qualitative interview all family medicine practitioners and oncologists declared that they avoided 'ethical issues' such as abandoning curative treatment for palliative/ hospice care and planning for death.

iv. Only $37 \%$ of doctor-respondents said that they frequently, or more often, "encourage my terminally-ill patients to draw up Advance Medical Directives".

v. In Israel, family members have by custom had a special role in communicating bad news. Although the 2005 Act requires that physicians disclose diagnoses first to patients themselves, whether the family agree or not, it has long been culturally approved that family members receive the information before patients, and families are requested to decide how and to what degree the patient should be told. Thus, while family members typically receive full medical information, including incurability and estimated prognosis, patients receive information gradually, and often partially, based on their preferences.

\section{Why do Patients not get the Truth?}

Potential obstacles to truth-telling reflect attitudinal, informational, economic, societal, and system barriers that are perceived differently by patients, physicians, and health care administrators. Last but not least, we should not forget that every doctor brings his/her own personal values onto the ward.

\section{Beliefs/Attitudes}

Over $77 \%$ of doctors believed that "concealing information from the patient can sustain his/her hope and prevent harm".

a) Almost $70 \%$ of doctors agreed in principle that "A multiplicity of treatment options is an obstacle to holding a conversation with the patient about end-of-life and a change in treatment goals".

b) Israeli oncologists are trained to cure and hate to admit failure in this regard. Respondents said to me:

c) "Telling a patient their treatment goal has changed is not an automatic thing with me. It's easier to mend a broken leg or give antibiotics, easier to play the role of healer rather than talk about death, with all its sense of medical failure."

d) "We have been taught to treat to the end. I never give up. Nowadays I have a wide range of treatment options I can offer."

Doctors' knowledge of the Terminally-Ill Patients Act, palliative care, and EoL Planning The Act:

a) The great majority of respondents reported being given no formal training in the provisions of the Act. They picked up information about it at conferences or study days but had not studied it deeply or systematically.

b) Those doctors who had a more thorough knowledge of the Act's provisions said, nonetheless, that it was complicated and hard to understand. Less than $30 \%$ of doctors felt "that I have mastered the provisions of the Terminally-Ill Patients Act". No more than $28 \%$ were aware of the Act's definition of 'terminally-ill'. Most doctors reported that they were not in a position to initiate an end-of-life conversation with a patient because the Act was not clear enough on when curative treatment should give way to end-of-life care. $61 \%$ were unable to distinguish accurately between 'hospice care', 'terminal care', 'palliative care' and 'supportive care'.

c) Doctors versed in the Act and the various aspects of palliative care had positive attitudes to truth telling and palliative care;

d) Doctors trained in palliative care and the Act had considerably more knowledge about starting/ transitioning to palliative care than doctors without this training. They also knew more about the ethical issues associated with the Act.

e) The more doctors know about the effects of telling patients the truth the more positive their attitudes to doing so.

\section{Palliative Care}

a) Doctors trained in palliative care were, overall, more positive in their attitudes to that form of care and its component elements;

b) Almost $70 \%$ held in principle that "A multiplicity of treatment options is an obstacle to holding a conversation with the patient about end-of-life and a change in treatment goals".

c) $72 \%$ agreed that they "fear that referring a patient to hospice care accelerates their death". What the doctors may in fact be afraid of, without admitting it in so many words, is euthanasia (see next finding);

d) $69 \%$ agreed with the statement that "Not infusing liquids into the patient in hospice care symbolizes for me that this form of care shortens life".

e) The more they know about palliative care the more positive their attitudes to it and to telling patients the truth about their prognosis. 
f) Only 54\% of the doctors agreed that "Terminally-ill patients should get palliative care in the last 6 months of their life", i.e. the point in time when palliative care should begin and which is core to the 2005 legislation but more than half the doctor-respondents were unaware that its timing had been so fixed.

\section{EoL Planning}

a) $91 \%$ of doctors felt that their "limited ability to predict when a patient will die holds me back from initiating an endof-life conversation", that is, they felt the patient was not terminally-ill enough.

b) $88 \%$ felt that their "lack of time is an obstacle to holding difficult end-of-life conversations".

c) $93 \%$ of doctors felt that their "lack of communication skills training is an obstacle to holding end-of-life conversations".

d) Doctors felt that, lacking knowledge about palliative care, it was best they shied clear of EoL conversations with patients for fear of doing them harm.

\section{Lack of Training}

a) Almost $70 \%$ of doctors agreed in principle that " $\mathrm{A}$ multiplicity of treatment options is an obstacle to holding a conversation with the patient about end-of-life and a change in treatment goals". Yet this "multiplicity of treatment options" is a sign of progress in healthcare, in that it provides doctors more treatment options to offer a patient than was the case in the past. In other words, they had not been trained in a modern-day approach to EoL care and treatment.

b) Two-thirds of doctors agreed that "A doctor's work with terminally-ill patients is made more complicated by ethical, social and religious issues".

c) Israeli oncologists perceived in themselves a general lack of the skills to handle EoL planning and care. As for which communication skills would make it easier to transfer patients to hospice care and get Advance Medical Directives drawn up the respondents cited the following:

d) 75\%-Medical training which teaches communication skills, not only medical procedures;

e) $72 \%$-The ability to explain a shift in the objective of care and treatment, not only a procedure's percentage success;

f) $70 \%$-The ability to put questions and to negotiate;

g) $66 \%$-Instruments for managing end-of-life conversations;

h) 55\%-Listening skills;

i) $30 \%$-Confidence in the way you practise medicine, not necessarily in your medical knowledge per se;

j) $20 \%$-Self-awareness.

\section{Conditions of Work/systemic Factors}

a) Organizational barriers included lack of staff and beds for hospice care, both in inpatient and at home, and hospice care not having a clear place on the agenda either of healthcare institutions or of the Israel Ministry of Health.

b) "Passing the Act does not mean it automatically gets implemented. The reality in oncology is that we are dependent on the media, on the state-sanctioned basket of drugs and therapies, on private health insurance policies, and so we find ourselves giving curative treatment to the end."

\section{Doctors' Emotional Resources}

a) Over $75 \%$ stated that "Disclosing the truth to the patient can cause me embarrassment and unease at how they (patients) will react"

b) Over two-thirds agreed that "An end-of-life conversation with the patient raises the issue for us of our own death. As physicians, fears of our own death influence extensively how we face up to the end-of-life issue".

c) "I do not initiate discussing such sensitive issues. I stick to the medical facts. I wait for the patient to raise such a matter and then I lay stress on, for example, the importance of quality of life.

d) "I wait for the patient or the family to raise such a matter. I know I should take the first step but in practice I am not up to it. I simply do not have the strength for it."

e) As for Advance Medical Directives: "I just cannot look the patient in the eyes and say to him. Let's fill out some forms about your death.' So I just answer questions when I'm asked them and where I think it necessary bring in a social worker."

\section{Patients' Attitudes}

a) Many patients do not want to hear the full truth about their condition (or at least that is what their family maintain);

b) Others want their physician to take the decisions alone;

c) Still others insist on every possible curative measure being attempted until the end and will listen to no other option.

\section{Family Resistance}

Almost every doctor agreed that "Sometimes it is the family that is the main obstacle to referring a patient to hospice care". Yet the Act lies down that if a patient is cognitively competent to take decisions for himself/herself the family has no right to prevent a doctor discussing different care options with the patient.

\section{Not Clear who is Responsible for Telling the Patient the Truth}

Every doctor thinks it is another doctor's job to inform the patient of a change in treatment site or goals. Patients themselves, at least those treated in hospitals, have no such doubts: they expect their oncologist to break bad news, after all he/she and their team have usually been caring for the patient for some time. Unfortunately, the 2005 Act is no help: it lays the responsibility on the patient's "personal physician" but does not say which doctor occupies this role. 


\section{The Gap between What Doctors Declare and What they Practise}

We see a wide gap between doctors' principles or at least what they feel they ought to declare as their principles and their behavior in practice.

a) $80 \%$ of doctors reported that they "prefer to be told all the details of a patient's personal story". They wanted to know as much as possible about the patient's circumstances in order to manage their own situation vis-à-vis the patient. That is, they wanted more for themselves than they were willing to give the patient.

b) Only $37 \%$ of doctor-respondents said that they frequently, or more often, "encourage my terminally-ill patients to draw up Advance Medical Directives". Yet over 85\% of doctors agreed that "Every patient has the right to know how terminal their condition is and to have their Advance Medical Directives respected".

c) Almost every doctor agreed in principle that it was important to empower the patient by giving them information about changes in treatment goals, thus preventing their uncertainty, but in ward practice the great majority of doctors usually failed to observe this principle.

Variation by profession(oncologists v. home care specialists $v$. family doctors)

Oncologists tended to stress the difficulty of the Act's implementation: "Theoretically, the Act helps but it is hard to put into practice. "I am not the one to take hope away from my patients. If there is no choice then my preference is to talk with the family and not directly with the patient. As oncologists we prefer to keep making efforts up to the end or until the patient them self takes the initiative to talk about the end of life." The home care specialists were markedly the boldest in implementing the Act, while family doctors thought that implementing the Act was the oncologists' job. The home care specialists agreed with them that the oncologists bore the brunt of the responsibility for preparing the patient for the end but it is clear that those oncologists found this very problematic.

In talking about PC, home care specialists reported having more of the necessary skills and resources than oncologists and family doctors. This is perhaps unsurprising since it is the home care specialists who have chosen to face up to the issues of EoL planning and care and equipped themselves for that. One said: "None of my colleagues [hospital oncologists] has attained emotional awareness of their own death and so steer clear of end-of-life conversations."Home care specialists were markedly more willing to persist to the end with the issues raised by the Act in order to give their patients a more dignified death. For instance, they were more willing to give the patient the information which would enable them to make their own choices. They were correspondingly more worried by the advance of the disease bringing about cognitive deterioration, which would prevent the patient expressing their wishes, in which case a guardian or family members would have to make necessary choices.
By contrast, all family doctors and oncologists responded by shying away from such issues; Home care specialists (and only home care specialists) were unafraid to face up to whatever might occur in an EoL conversation perhaps because they appreciated better what their patients wanted a true prognosis of the time left to them, to discuss their quality of life and the circumstances of their death. Home care specialists were more open to ethical problems: "I cope with any issue that arises and even broach the subject as part of my patient intake. I want to give the patient the best care possible and so I need to know their wishes and we talk about that in team staff meetings." This multidisciplinary approach to ethical issues is a hallmark of home care: "Any issue that comes up, no matter how difficult, we face up to it as a team so that we provide the best quality of life we can."

The knowledge displayed in the responses to the quantitative questionnaire about starting/ transitioning to palliative care differed significantly by specialism-doctors working in home care and family medicine know markedly more than oncologists. The same is true with respect to telling patients the truth oncologists know the least of the three specialism groups. And oncologists also score lowest on attitudes to telling patients the truth with family medicine specialists having the most positive attitudes. On knowledge about the provisions of the Terminally-Ill Patients Act, it was the family medicine specialists who scored lowest and the home care experts who scored highest

\section{Discussion}

Israel's deficiencies in providing dying patients the quality and place of death they would prefer threatens to become a national issue of disrespect for patients' and their wishes for death with dignity. Part of the problem is that Israel is very much a multicultural society. If advanced EoL and palliative care are to expand it has to find a way to adapt its principles to divergent cultural and religious beliefs, practices and customs.

\section{The Connection between Truth-Telling Per se and Truth Telling about Palliative Care}

Surely it is just to argue that not telling a patient about the possibilities of palliative and hospice care and not giving them the opportunity to discuss these matters and plan their coming care and treatment and death, surely this is not telling them a very significant part of the truth they should know. Truth-telling and EoL conversations can you have one without the other? Further, if an oncologist is ignorant, or largely so, of the provisions and requirements of the Terminally-Ill Patients Act then he or she is quite unequipped and unable to tell their patients all the truth they should know.

\section{The Consequences of Non-Truth Telling}

Truth-Telling as Patients' Right and Doctors' Obligation: Open and candid communication with the patient is the heart and soul of palliative care and the basis of doctor-patient trust. A patient suffering from a life-threatening illness deserves full, accurate and honest information about his condition but the findings show that relatively few patients get this. As soon as the patient does not 
receive honest, straightforward information the decision-making process is distorted. They cannot plan autonomously for their own future. It is the patient's right to choose how they will be treated (or not) and how they will die. It is their right to issue Advance Medical Directives. Not given full information about their medical condition and the options available to them, they cannot decide if they want curative treatment 'to the bitter end' or prefer the dignity and quality of life of hospice care. Non-truth-telling is a serious obstacle to the transfer of terminally-ill patients to palliative care and to other key elements of EoL care. EoL decisions are postponed until too late so that the benefits of palliative and hospice care are not fully exploited. Relatively few patients get the chance to draw up Advance Medical Directives, or discuss the option of hospice care and their place of death. The findings of the present study make it abundantly clear that if the oncologist does not take the initiative to broach the issue of Advance Medical Directives they will in most cases not be drawn up and registered.

Truth-Telling does not Cause Harm to Patients: On the contrary, most patients want to be involved in decision-making but doctors' awareness and attitudes on this issue and their lack of the communications skills which would help them be open with the patient often deprives patients of this right. Most patients prefer the truth and want it undecorated by euphemism and medical jargon. They want to talk about their quality of life and the circumstances of their death. Doctors frequently censor information they give to patients about their outlook on the grounds that what someone does not know cannot harm them [4] but avoidance of communication about the reality of a patient's situation does not protect them from experiencing considerable the psychological distress of uncertainty [5]. At the heart of any patient-centered approach is the need to understand the meaning of the illness for the patient, a central goal of any whole-person approach to end-oflife care [6]. In other words, doctors must learn how to listen fully as much as to speak truthfully. He/she must be willing to listen to the patient's views, fears and preferences for their future care and treatment. This is perhaps even harder for them than to do most of the talking themselves.

\section{Oncologists' Training Needs}

A notable lack mentioned especially by oncologists was training in the skills needed for managing end-of-life conversations: all said this was not a part of current training programs and this and the uses of palliative care ought to be given more place in medical training. Few Israeli medical schools and even fewer residency training programs mandate courses or clinical experience in endof-life care. Palliative care is not taught in basic medical training. Medical students, as noted at the beginning of this paper, frequently do not feel prepared to discuss end of-life issues with their patients and physician surveys have demonstrated a desire for ongoing education in this area [7]. In Israel, there are no formal courses in palliative care in doctors', nurses' and social workers' basic training. We cannot ignore that attitudes and knowledge may be markedly affected by medical education. Studies have shown that medical students who complete clinical rotations and courses in palliative care feel more comfortable with death and caring for dying patients [8].
The differences between three professions involved in EoL care displayed in the findings set out above demonstrates too the effectiveness of specifically designed training, although we cannot rule out that the very choice of profession results to some extent from individual beliefs and choices. The UK General Medical Council's [9] second edition of Tomorrow's Doctors recommended core teaching on 'relieving pain and distress, together with care of the terminally-ill' [2]. The UK Department of Health too has recently highlighted the need to educate all health care professionals to try and improve 'end-of-life care' and the third edition of Tomorrow's Doctors reiterates the need for students to be prepared to care for patients at the end of life GMC , [10].

\section{Giving knowledge Does not Necessarily Alter Beliefs}

Firstly, we need to state that some training clearly works. We have seen that doctors trained in palliative care and the 2005 Act knew much more about and had far more positive attitudes towards core elements of good EoL care and treatment. However, it would seem that it is harder to use training to alter doctors' attitudes than to increase and improve their knowledge. Although some studies have assessed physicians' knowledge and attitudes concerning various aspects of terminal care few have examined the effect of knowledge and attitudes on actual physician practice on the ward (nor has the present study, unfortunately) , and the results vary [11]. In a study of pain management practices of physicians the authors found no evidence that knowledge or attitudes about pain medication were associated with prescribing behaviours [12]. However, in three other studies which examined hospicereferral patterns, physicians' attitudes concerning disclosure and communication were associated with hospice-referral behaviours [13].

It is clear that education is unlikely alone to substantially change practice patterns [14]. Ideally, education would be one component of a more comprehensive systems-change approach. Empathic and compassionate communication with the patient requires from the attending physician not only the readiness and skills for this difficult task but a considerable degree of self-awareness. It will be critical for all palliative care experts to spend $40 \%-50 \%$ of their time educating and supporting other health care professionals and community support systems, in addition to providing consultation and direct patient/ family care [15]. It is clear that when doctors blame their lack of time for not broaching EoL conversations that the true explanation lays elsewhere. Some doctors are self-aware of this inability but many are not and need self-awareness training. For this to change doctors need to start asking themselves why they hold the attitudes they do and whether they are the ones most suited for their patients' welfare. It is vital too that trainees be active participants in their training, which will include role play, exercises in reflectivity, case analyses, maintaining a personal journal, lectures, and the analysis of video clips and films.

\section{The gap between respondents' declared beliefs and actual ward practice}

What does this gap mean or imply? Given that respondents' answers to the intensive qualitative interview were on the whole markedly more negative and sombre than the answers to the self- 
administered quantitative questionnaire; one possibility is that it was far harder to give self-deceiving answers to a knowledgeable interviewer than to a sheet of paper. A second possibility is that many respondents said what they thought the researcher wanted to hear or what they thought they ought to say. A third possibility is that the respondents are genuinely conflicted, that many feel that what they find themselves doing is not what ideally they would want to do,

\section{Conclusion and Recommendations}

\section{Shared Responsibility/Teamwork}

Oncologist as 'commander': The present study has demonstrated that leaving the oncologist in sole charge of hospitalsited end-of-life care is a recipe for failure in terms of truth telling. From my own long experience it is fear of what might make its appearance in an EoL conversation that deters most oncologists from this central component of modern patient-centred EoL care. Yet shared decision-making by all members of the multidisciplinary team would take some of the responsibility off oncologists as well as ensure a higher quality of decision-making. This widening of the 'circle of responsibility' to other hospital professionals, including nurses, social workers, home care coordinators, palliative care physicians, psychiatrists, psychologists and spiritual care specialists, each with their own input and experience, is invaluable [16]. The caregivers of patients in a hospice setting perceive nurses and social workers as most helpful with the transition to hospice care [17].

The critical value of teamwork lies in this very fact that it avoids the oncologist feeling that he/she faces the patient and their family alone. Teamwork in in-patient care could also involve family doctors and hospice home care specialists, both of whom have demonstrated in the present study a universe of attitudes far more sympathetic to palliative care than oncologists display. The oncologists interviewed for the present study admitted to being untrained in team-working. They and other potential team members frequently have little awareness about each other's informational roles and responsibilities. Oncologists in particular need to understand the roles of other disciplines and the advantages of the interdisciplinary approach in health care [18]. Medical education and training, however, provides little or no preparation for interdisciplinary practice and this recommended teamwork is unlikely to succeed without training in co-working, coordination and communication. Researchers have suggested that attitudes and stereotyping must be addressed early in professional education. Fineberg et alwrite, "Learning together allows team members to experience the viewpoints, knowledge, skills, and particular pressures of colleagues in other disciplines."

\section{Sharing data/ decisions with the patient}

A common situation among doctors is that they cannot predict life-expectancy with sufficient accuracy and so fear to take responsibility for initiating an end-of-life conversation. This makes it all the more important that the doctor share his/ her knowledge with the patient so that the patient can plan for the end of their life. When the benefits of an intervention are not discussed and understood by patients it threatens not only their ability to participate in decision-making, but also the quality of the decisions made without their input. Patients in qualitative studies spontaneously mentioned their participation in various decisions, indicating that it is an issue that matters to them [19]. Seven studies have examined whether palliative care patients generally prefer collaborative roles in decision-making. Five of these studies used the same five-point scale about treatment decisions and according to these five studies between $40 \%$ and $73 \%$ of the 379 participants prefer to share treatment decisions with their physicians [20].

\section{The Israel Ministry of Health needs to take initiatives}

Training oncologists in the 2005 Act: The Ministry of Health has a commitment to setting standards for the study and mastery of the provision of the 2005 Act. In practical terms doctors' mastery of the 2005 Act is currently mediocre and their attitudes to it and to the principles of palliative care embodied in it are even more negative. The Ministry of Health should require doctors to take periodic short study courses and/or longer training programs in the implementation of the Act and this has to be regularly enforced: doctors should be given positive and negative feedback and penalized if necessary.

Failings of the Act: The 2005 Act makes the "personal physician" responsible for informing the patient of a change in treatment goals, (but does not say who the personal physician is). The Ministry of Health must make it clear to hospital oncologists that a key component of their responsibility as the chief provider of care and treatment to terminally-ill patients is their duty from beginning to end to maintain regular and open communication with patient and family and build up relations of trust so that, at the required moment, they, the doctor, are in a position to open an endof-life conversation. In that conversation they must be equipped to, if necessary, persuade/inform patient and family that treatment goals have to change from cure to palliation and preparation for death. The critical sensitivities involved in handling end-of-life care in a manner that supports the patient's dignity and autonomy make it likely that certain personality traits are needed in the oncologist. The national regulator has to give thought to how these traits can be encouraged and sustained [21,22].

\section{Recommendations formally submitted to the Israel Ministry of Health}

With the aim of having the findings of the present study applied to current practice a multidisciplinary panel was appointed (including the author) to submit recommendations for action to the Israel Ministry of Health. The panel drew up the following recommendations:

a) It is our opinion that the task of breaking the bad news to a patient that they have entered the category of the "terminally ill" should be given to the hospital specialist who has been treating the patient's illness. He/she would inform the attending physician that he/she intends to do break the news and cooperate with the attending physician in the community 
as necessary. To inform the patient of his/her having entered this category and of their right to draw up Advance Medical Directives.

b) According to doctors the 2005 Act's definition of a 'terminally-ill patient' is insufficiently clear. Indeed, to determine that a person is definitely "terminally-ill" is extremely problematic. Medicine is not mathematics and this determination cannot be made with the required certainty. The Ministry of Health must therefore revisit and review the current definition of a 'terminally-ill patient'.

\section{Acknowledgement}

I acknowledge here the assistance of Nahum Steigman in translation, and structural and linguistic editing.

\section{References}

1. Pergert P, Lützén K (2012) Balancing truth-telling in the preservation of hope: a relational ethics approach. Nurs Ethics 19(1): 21-29.

2. Gibbins J, McCoubrie R, Forbes K (2011) Why are newly qualified doctors unprepared to care for patients at the end of life? Med Educ 45(4): 389399.

3. (1996) Ministry of Health, Patients' Rights Act, 1996, Jerusalem, Israel.

4. Slort W, Schweitzer BP, Blankenstein AH, Abarshi EA, Riphagen II et al. (2011) Perceived barriers and facilitators for general practitionerpatient communication in palliative care: a systematic review. Palliat Med 25(6): 613-629.

5. Fallow field LJ, Lipkin M, Hall A (1998) Teaching senior oncologists communication skills: results from phase 1 of a comprehensive longitudinal program in the UK. J Clin Oncol 16(5): 1961-1968.

6. Larson DG (2000) End-of-life conversations: evolving practice and theory. JAMA 284(12): 1573-1578.

7. Kutner JS, Chomiak A, Kramer A (2003) Palliative care education: an intervention to improve medical residents' knowledge and attitudes. J Palliat Med 6(3): 391-399.

8. Peng JK, Chiu TY, Hu WY, Lin CC, Chen CY, et al. (2013) what influences the willingness of community physicians to provide palliative care for patients with terminal cancer? Evidence from a nationwide survey. Jpn J Clin Oncol 43(3): 278-285.

9. (2002) General Medical Council 2002. Tomorrow's Doctors: Recommendations on Undergraduate Medical Education, $\left(2^{\text {nd }}\right.$ edn), London, UK.
10. (2009) General Medical Council, 2009. Tomorrow's Doctors: Outcomes and Standards for Undergraduate Medical Education. ( $3^{\text {rd }}$ edn), London, UK.

11. Gardiner C, Gott M, Ingleton C, Hughes P, Winslow M, et al. (2012) Attitudes of healthcare professionals to opioid prescribing in end-oflife care: a qualitative focus group study. J Pain Symptom Manage 44(2): 206-214.

12. Bruera E, Neumann CM, Mazzocato P, Stiefel F (2000) Attitudes and beliefs of palliative care physicians regarding communication with terminally ill cancer patients. Palliat Med 14(4): 287-298.

13. Bradley EH, Cramer LD, Bogardus ST, Kasl SV, Johnson Hurzeler R, et al. (2002) Physicians' ratings of their knowledge, attitudes, and end-of-lifecare practices. Acad Med 77(4): 305-311.

14. Dalal S, Palla S, Hui D, Nguyen L, Chacko, et al. (2011) Association between a name change from palliative to supportive care and the timing of patient referrals at a comprehensive cancer center. The Oncol theoncologist 16(1): 105-111.

15. Smith TJ, Temin S, Alesi ER, Abernethy AP, Balboni TA, et al. (2012) American Society of Clinical Oncology provisional clinical opinion: the integration of palliative care into standard oncology care. J ClinOncol 30(8): 880-887.

16. Wentlandt K, Burman D, Swami N, Hales S, Rydall A, et al. (2011) Preparation for the end of life in patients with advanced cancer and association with communication with professional caregivers. Psychooncology 876: 868-876.

17. Kelly KH, Eileen DH (2010) Helping patients with cancer prepare for hospice. Clin J Oncol Nurs 12(2): 180-188.

18. Fineberg IC, Wenger NS, Forrow L (2004) Interdisciplinary education: evaluation of a palliative care training intervention for pre-professionals. Acad Med 79(8): 769-76.

19. Bélanger, Rodríguez C, Groleau D, Légaré F, MacDonald ME, et al. (2011) Patient participation in palliative care decisions: An ethnographic discourse analysis. Int J Qual Stud Health Well-being 11: 10.

20. Schüklenk U, Van Delden JJM, Downie J, McLean SAM, Upshur R, et al. (2011) End-of-life decision-making in Canada: the report by the Royal Society of Canada expert panel on end-of-life decision-making. Bioethics 25(Sup1): 1-4.

21. (2005) Ministry of Health, Terminally-Ill Patients Act, 2005, Jerusalem, Israel.

22. (2010) Oxford Textbook of Palliative Medicine, (4 $4^{\text {th }}$ edn). In: G Hanks (Eds.), Oxford University Press, UK.
This work is licensed under Creative Commons Attribution 4.0 License

Submission Link: http://biomedres.us/submit-manuscript.php

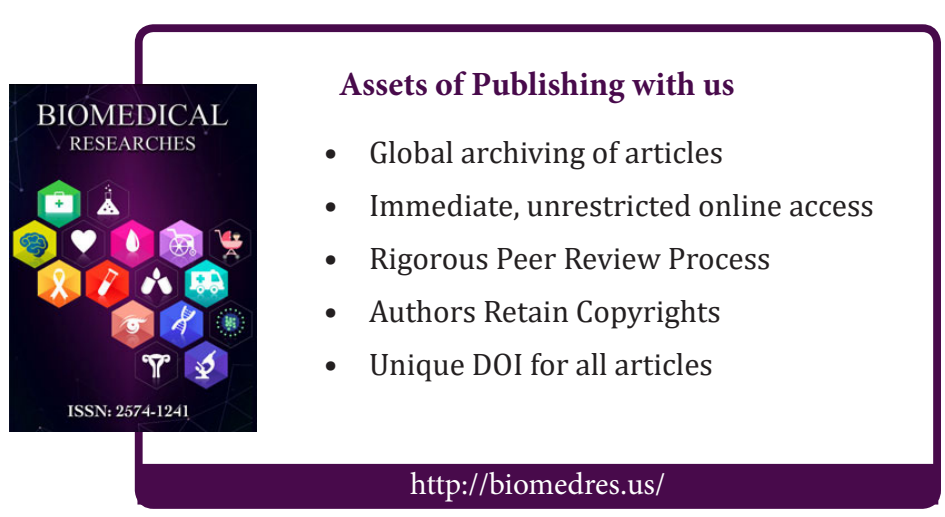

